\title{
Efficacy of Albendazole Against Soil-transmitted Helminthiasis among Children in Asia: Systematic Review
}

\author{
M. Mohd Faizal ${ }^{1,2}$, B. P.Anaanthan ${ }^{1,3}$, M. NurEzdiani ${ }^{1}$, M. N. Azmawati ${ }^{1}$,A. Norfazilah ${ }^{1}$, F. G. Hasanain ${ }^{4}$, Mohammad Safrree Jeffree $^{2}$, \\ Syed Sharizman Syed Abdul Rahim², Mohd Rohaizat Hassan ${ }^{1 *}$ \\ ${ }^{1}$ Department of Community Health, Universiti Kebangsaan Malaysia, Kuala Lumpur, 56000, Malaysia; ${ }^{2}$ Department of Community \\ and Family Medicine, Faculty of Medicine and Health Science, Universiti Malaysia Sabah; ${ }^{3}$ Department of Pharmacy, Hospital \\ Tuanku Ja'afar, 70300 Seremban, Negri Sembilan, Malaysia; ${ }^{4}$ Department of Community Medicine, International Medical \\ School, Management and Science University, Malaysia
}

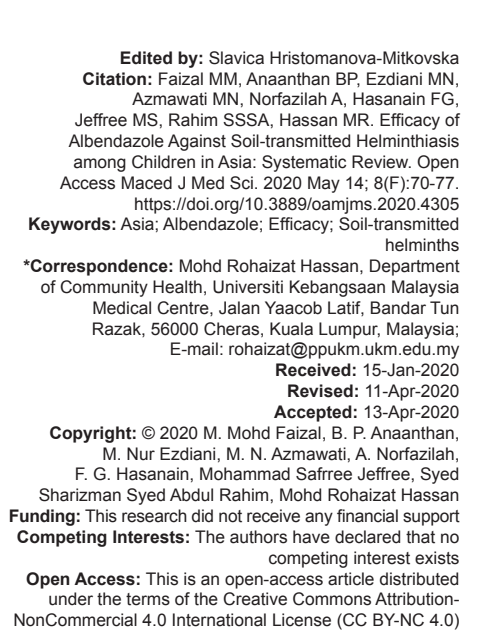

\section{Abstract}

BACKGROUND: The World health organization reported that 875 million children worldwide require antihelminth preventive chemotherapy annually. Vast majority of STH infections (67\%) and YLDs (68\%) occurred in Asia.

METHODS: A systematic search was performed for relevant titles, abstract, and keywords from Cochrane Library, PubMed, and Scopus around October 2018 based on the PICO strategy. Out of 173 papers that were evaluated final assessment for eligibility had yielded a total of five papers to be included for analysis covering period from 2013 to 2018 .

RESULTS: Of the five selected studies, three were randomized controlled trial, one was cohort and another one was described more like a quasi-experimental trial. All infection intensity showed improvement post-intervention. Four of the five studies used Kato Katz as diagnostic method with one combined it with Baermann techniques. One used McMaster egg counting method. All except one study tested albendazole efficacy in their study either alone or in combination with other chemotherapy such as diethyl carbazide or combining with education pamphlet. Egg reduction rate was reported as low as $63 \%$ and as high as $99.9 \%$.

CONCLUSION: In general, albendazole is efficacious enough to control STH.

\section{Introduction}

Soil-transmitted helminthisis consists of parasitic infections transmitted through soil. There are four types of helminth classified as soil transmitted helminthiasis; Ascaris lumbricoides, Trichuris trichiura, Ancylostoma duodenale, and Necator americanus [1]. Ascariasis, which is known as roundworm, in 2013 infects 804 million people, mainly children and adolescents. $T$. trichiura, also known as whipworm estimated to affect 477 million individuals, mainly with high prevalence and intensity in children's. In contrast, hookworm which consists of $A$. duodenale and $N$. americanus has highest intensity in adults, although children's are also affected. Hookworms combined affect 472 million people [1]. The WHO reported that 875 million preschool and school aged children worldwide requires annual antihelminth preventive chemotherapy annually [2].
There is a shift of total DALY of STH, whereby majority of them constitute from the upper-middle income, low-middle income, and low income in 1990 to now concentrated in the lower-middle income and lowincome countries [3]. Interestingly, vast majority of STH infections (67\%) and YLDs (68\%) occurred in Asia [4]. Mass drug administration (MDA) is a means of delivering safe and inexpensive essential medicines based on the principles of preventive chemotherapy, where populations or sub-populations are offered treatment without individual diagnosis [5]. WHO recommends the regular administration of preventive chemotherapy with albendazole or mebendazole as the main intervention for controlling soil-transmitted helminthiases [2]. To the best of our knowledge, up till this date, no review was done to address the efficacy of the therapy in Asia. Thus, this review was conducted to know the efficacy of albendazole when used as MDA in Asia on different subgroups of STH. 


\section{Methods}

The review was done based on the Preferred Reporting Items for Systematic Reviews and MetaAnalyses guidelines (PRISMA) [6]. Search was done in Cochrane Library, PubMed, and Scopus around October 2018. PICO strategy was performed to search for relevant titles, abstracts, and keywords. The studies were retrieved using keywords (children OR child OR preschool) AND (anthelminthics OR albendazole OR albendoral OR albenza OR andazol OR bundapar OR bilutac OR digezanol OR disthelm OR endoplus OR eskazole OR gascop OR lurdex OR metiazol OR valbazen OR zentel) AND Asia AND (efficacy OR cure rate OR egg reduction rate). The inclusion criteria were included (1) studies published since 2013; (2) English; and (3) has study design. Grey literatures were not searched.

The review was done by mainly 2 reviewers, one reviewer is medical doctor specialized in public health and other is a pharmacist and both have experience in conducting systematic review protocol. In the first stage, two reviewers independently screened the titles and abstracts for inclusion of all the potential studies. The studies were coded as either "retrieve" (eligible or potentially eligible/unclear) or "do not retrieve." As for the second stage, the full-text was retrieved and another two reviewers independently screened the fulltext, identified studies for inclusion, and stated reason for exclusion of the ineligible studies. The $3^{\text {rd }}$ reviewer was just a back up in case of any discrepancy.

Data extraction of the accepted studies were done using an Excel table with the following particulars: Author, title, publication year, country, objective of study, sample size, age group of study population, study design, mean infection intensity (before and after treatment), diagnostic method, drug used and dosage, parasite involved, treatment evaluation period, and efficacy which was based on either cure rate or egg reduction rate, other reported outcomes and conclusion. All randomized controlled trials (RCT) were assessed for the following quality criteria: Randomization methods, description of withdrawals and dropouts, and blinding. A numerical score between 0 and 5 was assigned as a measure of study design and reporting quality with " 0 " being the weakest and " 5 " designated as the strongest, based on the validated scale put forward by Jadad et al. [7] As for non-RCT paper, NewcastleOttawa Quality Assessment Scale (NOS) was used.

\section{Results}

\section{Literature search and study selection}

The search strategy yielded 173 literatures. Following removal of duplicate literatures, there were
170 articles left for screening. Further screening of the remaining titles and abstracts excluded another 152 studies which were not relevant to the study objective. The remaining 20 articles were retrieved to be assessed for eligibility and detailed evaluation. This excluded another 13 studies. The reasons for exclusion were unretrievable article, different intervention looked at, for example, not specific to albendazole or similar anthelminthic groups but other intervention, different outcome looked at, for example, malaria and not interventional study, for example, article on overview of hookworm infection and its management. Five remaining articles [8], [9], [10], [11] were included for the review. The flow diagram of the selection process in line with the PRISMA flow diagram [12] as shown in Figure 1.

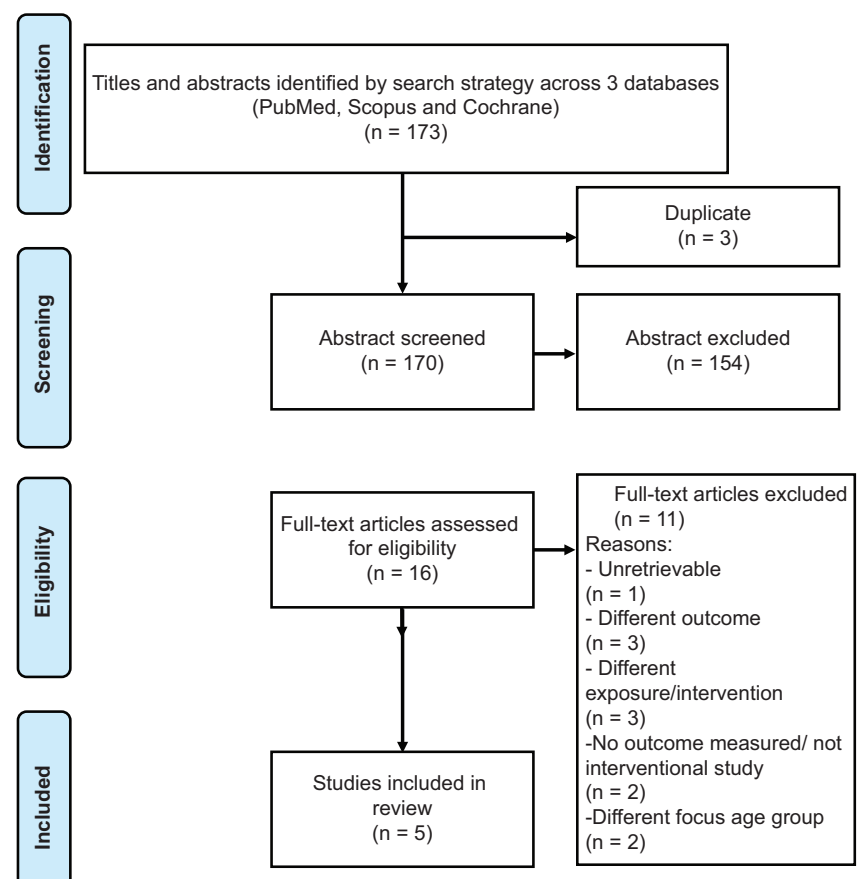

Figure 1: PRISMA flow diagram

\section{Study characteristics}

Table 1 listed the characteristics of the included studies. Of the five selected studies, three were RCT [8], [10], [11], one was cohort [13] and another one was described more like a quasi-experimental trial [9]. Two RCTs were done in China, one in Laos while the cohort study was done in India. The quasi trial was done in Cambodia and Vietnam. However, as mentioned earlier, these were two sites from six total sites in the trial - Brazil, Cameroon, Ethiopia, and United Republic of Tanzania. The three RCT studies involved participants ranging between 211 and 2179, the cohort study had 646 participants while the last trial involved between 69 and 211 participants in two sites in South East Asia from six sites globally. Participants age ranged were between 6 and 15 years old with means age majority was around 9 or 10 . Mean infection 

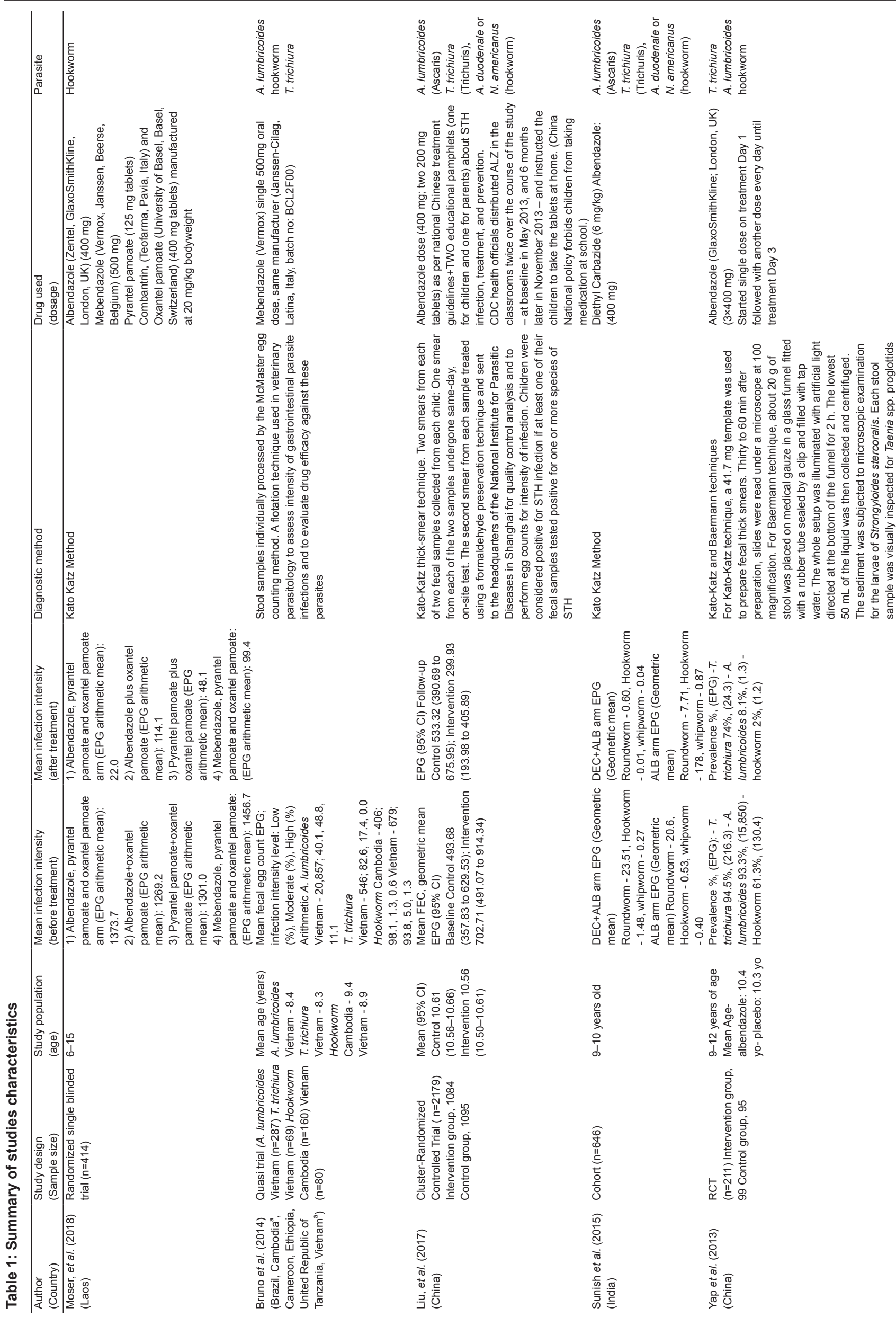

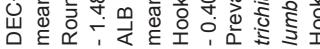

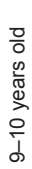

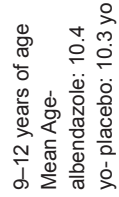

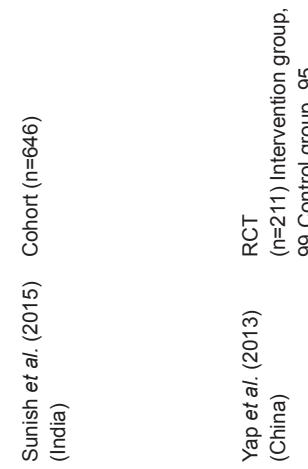




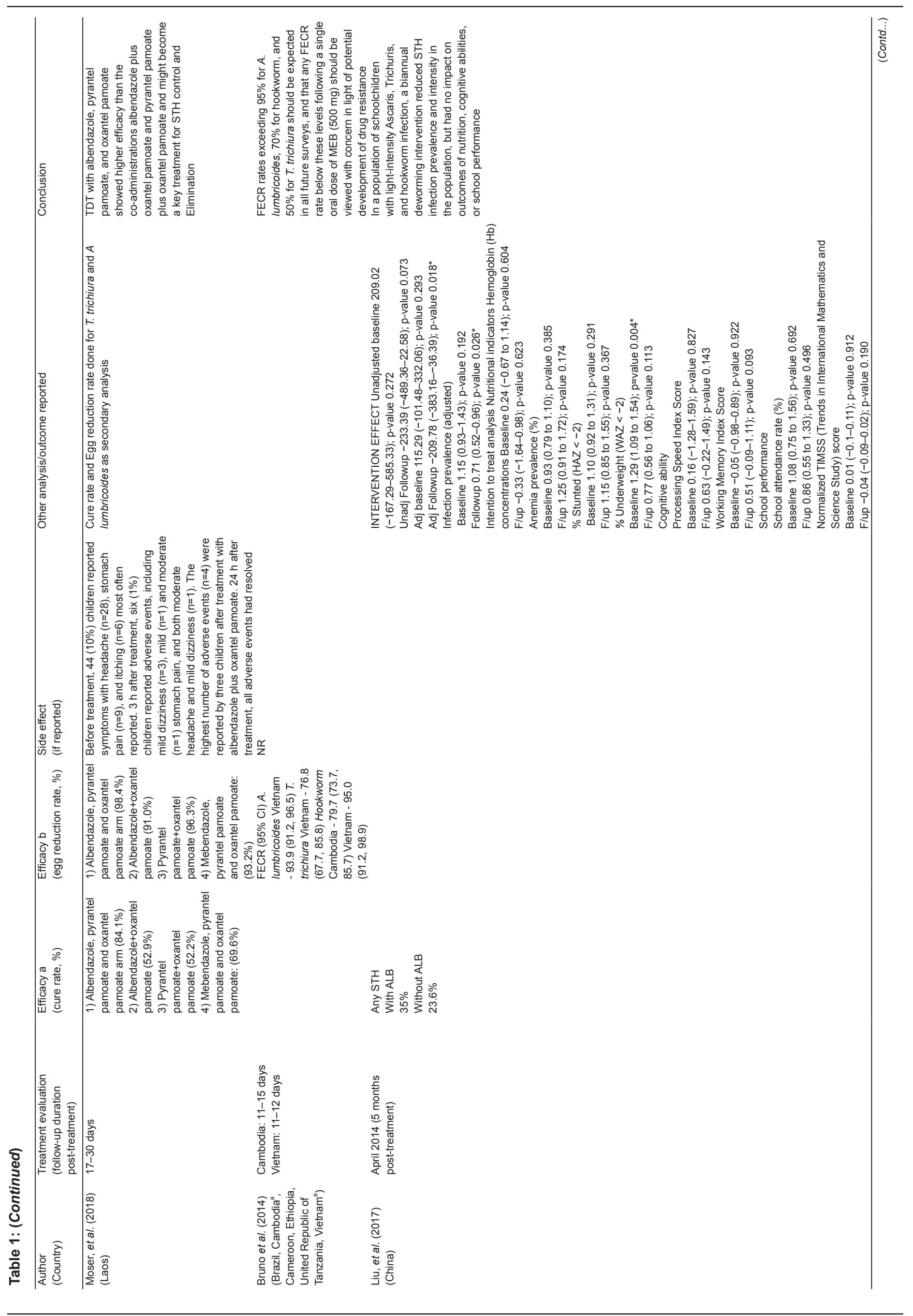

Open Access Maced J Med Sci. 2020 May 14; 8(F):70-77. 


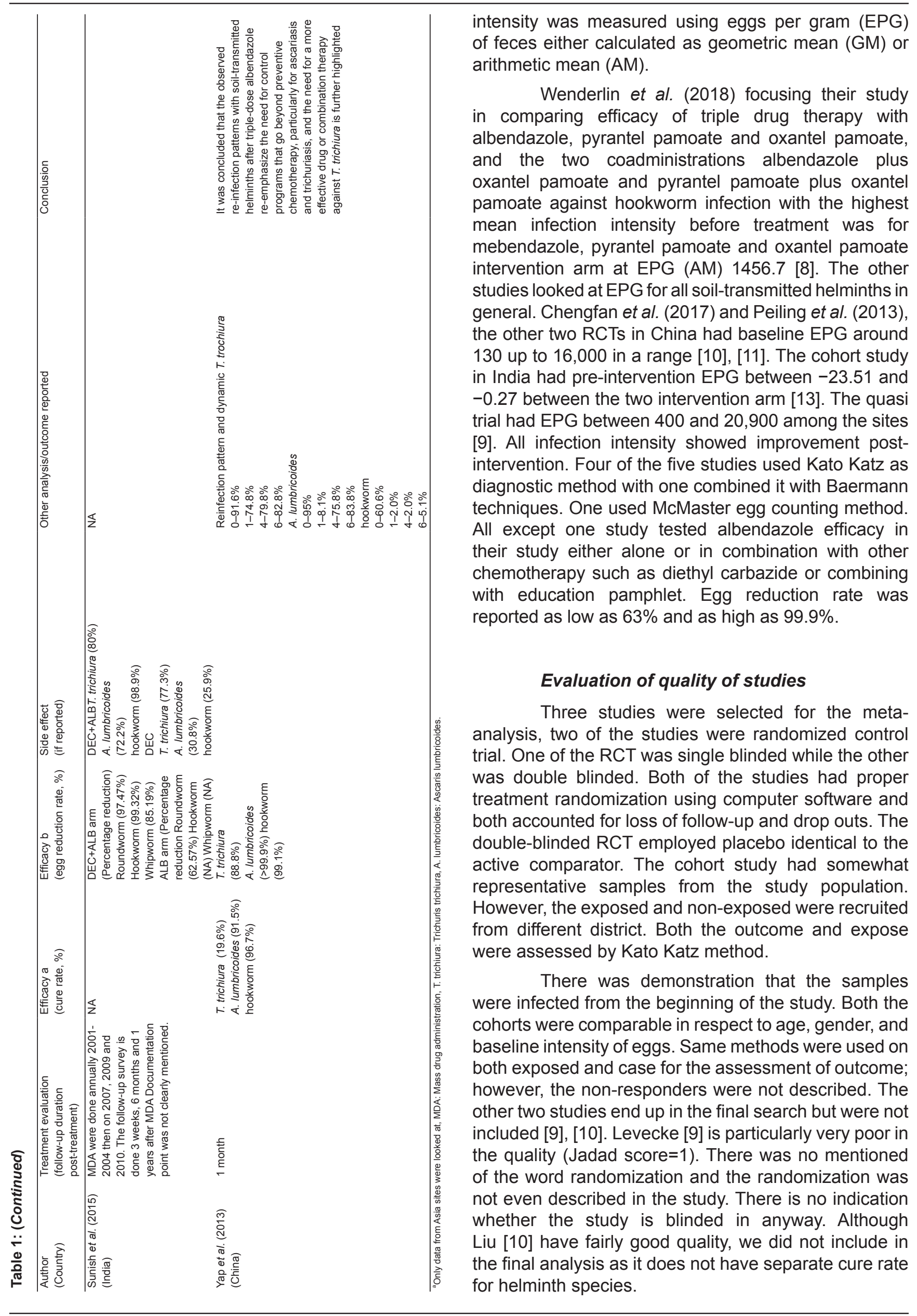

intensity was measured using eggs per gram (EPG) of feces either calculated as geometric mean (GM) or arithmetic mean (AM)

in comparing albendazole, pyrantel pamoate and oxantel pamoate, and the two coadministrations albendazole plus oxantel pamoate and pyrantel pamoate plus oxante pamoate against hookworm infection with the highest intervention arm at EPG (AM) 1456.7 [8]. The other studies looked at EPG for all soil-transmitted helminths in general. Chengfan et al. (2017) and Peiling et al. (2013), other two RCTs in China had baseline EPG around 130 up to 16,000 in a range [10], [11]. The cohort study India had pre-intervention EPG between -23.51 and [9]. All infection intensity showed improvement postintervention. Four of the five studies used Kato Katz as techniques. One used McMaster egg counting method. All except one study tested albendazole efficacy in their study either alone or in combination with other chemotherapy such as diethyl carbazide or combining education pamphlet. Egg reduction rate was reported as low as $63 \%$ and as high as $99.9 \%$.

\section{Evaluation of quality of studies} analysis, two of the studies were randomized control trial. One of the RCT was single blinded while the other was double blinded. Both of the studies had proper treatment randomization using computer software and the double-blinded RCT employed placebo identical to the active comparator. The cohort study had somewhat representative samples from the study population. However, the exposed and non-exposed were recruited from different district. Both the outcome and expose were assessed by Kato Katz method.

There was demonstration that the samples were infected from the beginning of the study. Both the cohorts were comparable in respect to age, gender, and aseline intensity of eggs. Same methods were used on however, the non-responders were not described. The other two studies end up in the final search but were not included [9], [10]. Levecke [9] is particularly very poor in the quality (Jadad score=1). There was no mentioned the word randomization and the randomization was whether the study is blinded in anyway. Although Liu [10] have fairly good quality, we did not include in the final analysis as it does not have separate cure rate for helminth species. 


\section{Main analysis}

The meta-analysis data using random-effect model to explore the efficacy of albendazole against STH among children in Asia are shown in Figure 2.

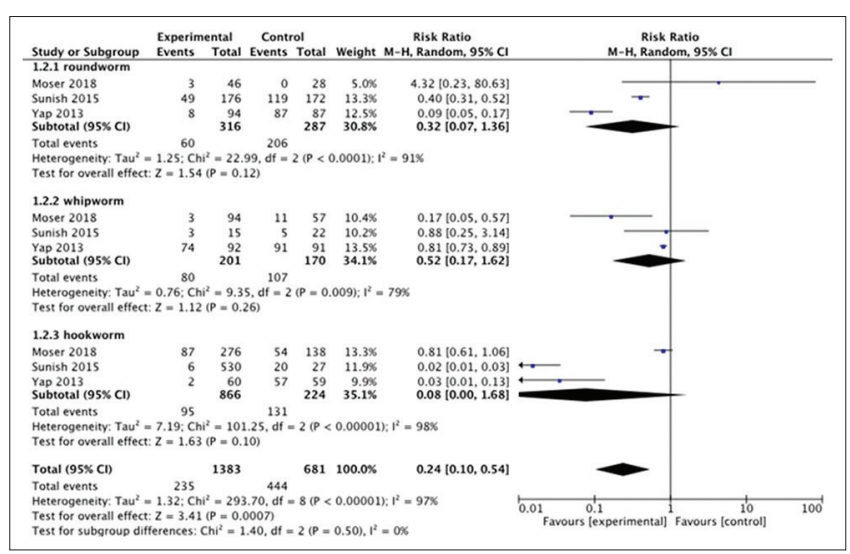

Figure 2: Forest plot analysis

The forest plot illustrates the spread of the three studies risk estimates and their confidence intervals $(\mathrm{Cl})$ in relation to the summary RR of meta-analysis. The Chi-square for the random-effect meta-analysis that test for equal variance between studies had a value of 293.7 ( $p<0.001)$. While $\mathrm{I}^{2}$ index which indicates level of heterogeneity was estimated to be $97 \%$. Based on the four studies, the pooled RR estimates showed that albendazole has better protective effect against STH compared to comparators $(\mathrm{RR}=0.24 ; 95 \% \mathrm{Cl}$ : 0.10-0.54).

\section{Discussion}

The review focused on the efficacy of albendazole against STH among children in Asia. Measure of the efficacy was done using the gold standard, either cure rate, or fecal egg reduction rate. In overall, the results showed that the intervention involving albendazole reduced infection prevalence relative to the control group. Out of five included studies in this review, only three were considered in meta-analysis [8], [11], [13]. All three studies subgrouped the STH according to parasites, namely, A. lumbricoides (roundworms), T. trichiura (whipworms), and hookworm. The forest plot analysis showed high heterogeneity of the studies with $\mathrm{I}^{2}=97 \%$. Subgroup analysis showed non-significant findings $(p=0.5)$, yet the overall effect showed $p<0.05(p=$ 0.007 ) which was significant. This can be explained by two reasons. First, the fundamental knowledge in interpreting the forest plot that due to smaller numbers (participants), $\mathrm{Cl}$ in subgroups will always be wider than those for overall effect [14]. Second, effect of the varied methods or compared groups in the studies. Two studies included in this meta-analysis did a comparison between drug and placebo [11], [13], while Moser et al. compared between two drugs [8]. This possibly had caused inconsistency of subgroups and overall effect. However, albendazole is less efficacious against whipworm. This finding supports similar result from the previous systematic review and study by Keiser and Utzinger (2008) [15] and Viswanath and Williams (2008) [16], respectively. Moreover, this result had proven that the emergence of drug resistance in controlling STH cannot be abandoned and requires more attention too.

In term of safety out of the five studies, only one reported side effects after initiation of treatment [8]. The side effects included dizziness, headache, and stomach pain, and all of them were only mild to moderate in severity. Symptoms had started as early as $3 \mathrm{~h}$ post-treatment and resolved within $24 \mathrm{~h}$. These symptoms were encountered in the intervention group using combination of albendazole and oxantel pamoate, thus it is difficult to determine which drug caused a particular side effect. This review was done focusing on Asian population, which is the major contributor of STH. The review search strategy was ensured to be more comprehensive using MESH keyword. This was hoped to be able to capture all possible studies. Apart from that, independent review by two reviewers allowed for lesser bias in assessing the studies. One reviewer is a pharmacist which strengthened the understanding on the pharmacotherapy looked at grey literature was not searched due to time constrain rendering to the possibilities of missing local unpublished data. The limitation of the current study is that it does not cover all Asian countries because of our inclusion and exclusion criteria and data availability for the review. Future studies need to include more Asian countries.

\section{Conclusion}

Albendazole was proven to be efficacious against STH, but more studies are required in exploring on whipworm less efficacious related issues such as drug resistant. To strengthen the review, inclusion of more databases and studies published earlier than 2013 should be considered.

\section{Acknowledgment}

The authors would like to thank the Universiti Kebangsaan Malaysia for sponsoring this work to be published. 


\section{Conflicts of Interest} of interest.

The authors declare that they have no conflicts

\section{References}

1. Jourdan PM, Lamberton PH, Fenwick A, Addiss DG. Soiltransmitted helminth infections. Lancet. 2018;391(10117):25265. https://doi.org/10.1016/s0140-6736(17)31930-x PMid:28882382

2. World Health Organization. Investing to Overcome the Global Impact of Neglected Tropical Diseases. Third WHO Report on Neglected Tropical Diseases. Geneva: World Health Organization; 2015. https://doi.org/10.1128/9781555818753. ch10

3. Stolk WA, Kulik MC, le Rutte EA, Jacobson J, Richardus JH, de Vlas SJ, et al. Between-country inequalities in the neglected tropical disease burden in 1990 and 2010, with projections for 2020. PLoS Negl Trop Dis. 2016;10(5):e0004560. https://doi. org/10.1371/journal.pntd.0004560 PMid:27171193

4. Pullan RL, Smith JL, Jasrasaria R, Brooker SJ. Global numbers of infection and disease burden of soil transmitted helminth infections in 2010. Parasit Vectors. 2014;7(1):37. https://doi. org/10.1186/1756-3305-7-37

PMid:24447578

5. Webster JP, Molyneux DH, Hotez PJ, Fenwick A. The contribution of mass drug administration to global health: Past, present and future. Philos Trans R Soc Lond B Biol Sci. 2014;369(1645):20130434. https://doi.org/10.1098/ rstb.2013.0434

PMid:24821920

6. Moher D, Liberati A, Tetzlaff J, Altman DG. Preferred reporting items for systematic reviews and meta-analyses: The prisma statement. PLoS Med. 2009;6(7):e1000097. https://doi. org/10.1371/journal.pmed.1000097

PMid:19621072

7. Jadad AR, Moore RA, Carroll D, Jenkinson C, ReynoldsDJ, Gavaghan DJ, et al.Assessing the quality of reports of randomized clinical trials: Is blinding necessary? Control Clin Trials. 1996;17(1):1-12. https://doi.org/10.1016/0197-2456(95)00134-4 PMid:8721797
8. Moser W, Sayasone S, Xayavong S, Bounheuang B, Puchkov M, Huwyler J, et al. Efficacy and tolerability of triple drug therapy with albendazole, pyrantel pamoate, and oxantel pamoate compared with albendazole plus oxantel pamoate, pyrantel pamoate plus oxantel pamoate, and mebendazole plus pyrantel pamoate and oxantel pamoate against hookworm infections in school-aged children in Laos: A randomised, single-blind trial. Lancet Infect Dis. 2018;18(7):729-37. https://doi.org/10.1016/ s1473-3099(18)30220-2

9. Levecke B, Montresor A, Albonico M, Ame SM, Behnke JM, Bethony $\mathrm{JM}$, et al. Assessment of anthelmintic efficacy of mebendazole in school children in six countries where soiltransmitted helminths are endemic. PLoS Negl Trop Dis. 2014;8(10):e3204. https://doi.org/10.1371/journal.pntd.0003204 PMid:25299391

10. Liu C, Lu L, Zhang L, Luo R, Sylvia S, Medina A, et al. Effect of deworming on indices of health, cognition, and education among schoolchildren in Rural China: A cluster-randomized controlled trial. Am J Trop Med Hyg. 2017;96(6):1478-89. https://doi.org/10.4269/ajtmh.16-0354

PMid:28093533

11. Yap P, Du ZW, Wu FW, Jiang JY, Chen R, Zhou XN, et al Rapid re-infection with soil-transmitted helminths after tripledose albendazole treatment of school-aged children in Yunnan, people's republic of China. Am J Trop Med Hyg. 2013;89(1):2331. https://doi.org/10.4269/ajtmh.13-0009

PMid:23690551

12. Moher D, Liberati A, Tetzlaff J, Altman DG. Preferred reporting items for systematic reviews and meta-analyses: The prisma statement. Ann Intern Med. 2009;151(4):264-9. https://doi. org/10.7326/0003-4819-151-4-200908180-00135 PMid:19622511

13. Sunish I, Rajendran $R$, Munirathinam $A$, Kalimuthu $M$, Kumar V, Nagaraj J, et al. Impact on prevalence of intestinal helminth infection in school children administered with seven annual rounds of diethyl carbamazine (DEC) with albendazole. Indian J Med Res. 2015;141(3):330-9. https://doi. org/10.4103/0971-5916.156622 PMid:25963494

14. Cuzick J. Forest plots and the interpretation of subgroups Lancet. 2005;365(9467):1308. https://doi.org/10.1016/ s0140-6736(05)61026-4 PMid:15823379

15. Keiser J, Utzinger J. Efficacy of current drugs against soiltransmitted helminth infections: Systematic review and metaanalysis. JAMA. 2008;299(16):1937-48. https://doi.org/10.1001/ jama.299.16.1937

PMid: 18430913

16. Viswanath A, Williams M. Trichuris Trichiura (Whipworm, Roundworm). Treasure Island, FL: StatPearls; 2018. 


\section{Supplemental Material}

\begin{tabular}{|c|c|c|c|c|c|c|}
\hline Source (Location, year trial was implemented) & $\begin{array}{l}\text { Age (years } \\
\text { old) }\end{array}$ & $\begin{array}{l}\text { Diagnostic } \\
\text { approach }\end{array}$ & $\begin{array}{l}\text { Treatment } \\
\text { evaluation }\end{array}$ & Study design & $\begin{array}{l}\text { Quality assessment } \\
\text { (Jadad) }\end{array}$ & $\begin{array}{l}\text { Quality assessment } \\
\text { (Newcastle-Ottawa Study) }\end{array}$ \\
\hline Moser et al., 2018, Laos 2018 & $6-15$ & Kato Katz & $\begin{array}{l}17-30 \text { days after } \\
\text { treatment }\end{array}$ & Single-blinded RCT & 3 & NA \\
\hline Yap et al., 2013 China & $9-12$ & $\begin{array}{l}\text { Kato Katz and } \\
\text { Bauermann }\end{array}$ & $\begin{array}{l}1-6 \text { months after } \\
\text { treatment }\end{array}$ & Double-blinded RCT & 5 & NA \\
\hline Sunish et al., 2015 India & $9-10$ & Kato Katz & $\begin{array}{l}10 \text { years } \\
(2001-2010)\end{array}$ & Cohort & NA & Good quality \\
\hline $\begin{array}{l}\text { Levecke et al., } 2014 \text { Brazil, Cambodia, Cameroon, } \\
\text { Ethiopia, United Republic of Tanzania, and Vietnam }\end{array}$ & $4-18$ & McMaster & $\begin{array}{l}7-15 \text { days on } \\
\text { average }\end{array}$ & Multicenter clinical trial & 1 & NA \\
\hline Liu, 2017 & $9-11$ & Kato-Katz & 1 year later & Cluster-randomized trial & 4 & NA \\
\hline
\end{tabular}

